\title{
Cement Rotary Kiln Fault Diagnosis Method Based on Case-Based Reasoning Shihui LIU ${ }^{1, a}$, Qingjin MENG ${ }^{2, b}$ \\ ${ }^{1}$ School of Electrical Engineering, University of Jinan, Jinan 250022, China \\ ${ }^{2}$ School of Electrical Engineering, University of Jinan, Jinan 250022, China \\ ahailanglsh@126.com, bcse_mqj@ujn.edu.cn
}

Keywords: Fault Diagnosis, Case-Based Reasoning, Cement Rotary Kiln, Similarity Calculation

\begin{abstract}
In view of the fact that the complicated structures, a lot of process parameters, a lot of fault types and a lot of fault cases of cement rotary kiln, Case-Based Reasoning (CBR) method is put forward to use to diagnose for cement rotary kiln. CBR fault diagnosis model is established. Object-oriented method is used to express fault cases. Organizing and retrieval the case library of cement rotary kiln and similarity calculation are made key research. Put forward the fault case study adjustment mechanism. The practical example is given.
\end{abstract}

\section{Introduction}

Cement rotary kiln is one of the most important equipment of new dry process cement production. Its safety, stability and efficiently running can directly affect the quality of cement production. At present, the fault diagnosis of cement rotary kiln are mainly rely on artificial diagnosis, meanwhile, with the rapid development of intelligent diagnosis technology, the advanced intelligent diagnosis technologies are used in the fault diagnosis system of cement rotary kiln. Based on case reasoning diagnosis system is a kind of expert system, which is widely applied in fault diagnosis and prediction ${ }^{[1,2]}$. The design of intelligent diagnosis system needs to correct and efficient, so diagnosis method that suitable for cement rotary kiln has the very vital significance. In this paper based on the basis of common fault cases of cement rotary kiln discussing the method of cement rotary kiln fault diagnosis based on case-based reasoning.

\section{Case-Based Reasoning (CBR) and the Mechanism of Model}

Diagnosis method based on case-based reasoning is used to deal with fault cases (including fault happened, cause, characteristics, processing measures, etc.) stored in the fault, in the case when there is a new fault occurs, through the fault case retrieval, query and the current fault before the same or similar cases, and then apply the previous fault handling measures or adjust form suitable for the current fault processing method, will handle the new fault after stored in the fault case, convenient for later retrieval. Generally speaking, according to search the previous fault cases solve the same or similar problems.

Figure 1 is the CBR fault diagnosis model. 


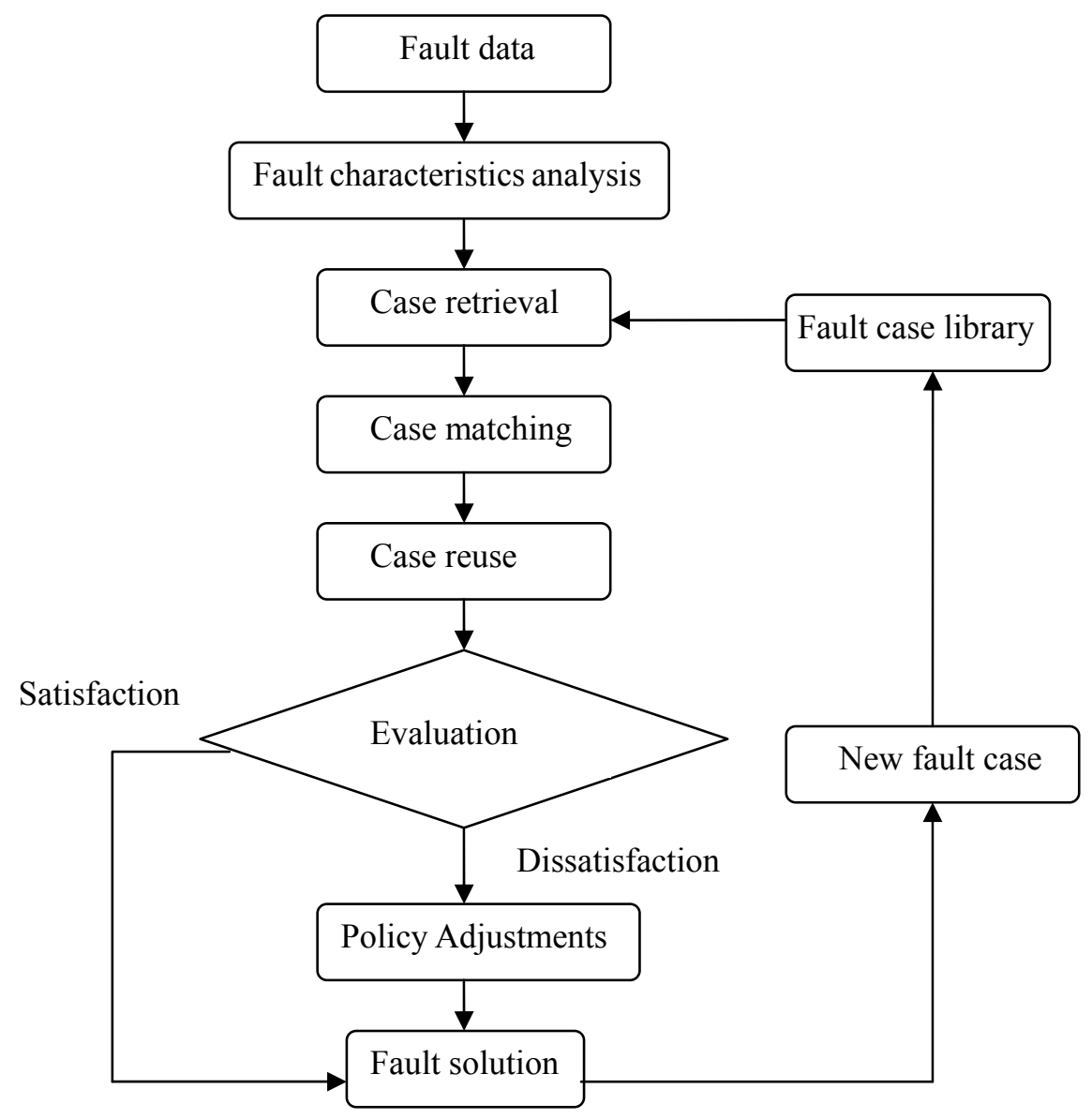

Figure 1.CBR fault diagnosis model

In CBR fault diagnosis model, the core problems are representation, organization, index case and case similar features matching.

\section{Build Fault Case Library}

\section{The Object-oriented Fault Case Representation Method}

Object-oriented method is used for programming at beginning, which greatly improves the efficiency of program execution. As people on the study of object-oriented method, the object-oriented program is not only used for programming, the system analysis and design phases, also began to adopt the method of object-oriented. Fault case is expressed as an object; attributes of the object used to represent characteristics of fault case information; object's method is used to represent the fault case retrieval and reuse, revisions and so on. So, introduces the concept of object-oriented representation of fault cases, a failure case can be expressed as a quad:

$$
\mathrm{C}=<\mathrm{D}, \mathrm{S}, \mathrm{M}, \mathrm{E}>
$$

In this quad, $\mathrm{D}=\left\{\mathrm{d}_{1}, \mathrm{~d}_{2}, \ldots, \mathrm{dm}\right\}$ is a non-empty finite set, used to describe the fault cases information; $\mathrm{S}=\left\{\mathrm{s}_{1}, \mathrm{~s}_{2}, \ldots, \mathrm{s}_{\mathrm{n}}\right\}$ is a non-empty set, used to describe the fault cases symptom properties; $M$ describes the processing method of the fault case; E describes the evaluation of fault cases after treatment. Therefore, using the concept of object-oriented, a typical failure case structure can be defined as the following.

\section{FaultCase} \{

CaseID; $\quad$ //fault case number 


$\begin{array}{ll}\text { FaultModel; } & \text { // fault case type } \\ \text { SymptomSet; } & / / \text { fault case symptom } \\ \text { Causation; } & \text { // fault case causation } \\ \text { Action; } & \text { // fault case action } \\ \text { Evaluation; } & \text { //evaluation } \\ \text { Similarity; } & \text { //similarity }\end{array}$

The existing fault symptoms are described as below:

F001---Device Name: cement rotary kiln (S01), calciner (S02), grate cooler (S03);

F002---Failure Parts: kiln speed reducer (S01), kiln roller bearings (S02), cement rotary kiln motor (S03);

F003--- kiln motor current amplitude, the unit A: 850-950 (S01), 950-1050 (S02), 1050-1150 (S03), 1150-1250 (S04);

F004---kiln shell temperature, the unit ${ }^{\circ} \mathrm{C}$ : 250-350 (S01), 350-450 (S02), 450-550 (S03), 550-650 (S04);

F005---kiln roller bearing shell temperature, the unit ${ }^{\circ} \mathrm{C}: 150-200$ (S01), 200-250 (S02), 250-300 (S03), 300-350 (S04).

In order to facilitate information mentioned above, use the form of $<,>$.For example, $<$ F001, S01 $>$ express equipment of cement rotary kiln, $<$ F003, S02 $>$ express kiln motor current amplitude within 950-950 A.

Using the object-oriented fault case representation method to describe above-mentioned case.

FaultCase

\{

CaseID="A0001";

FaultModel=" Roller bearing wear";

SymptomSet $=(<\mathrm{F} 001, \mathrm{~S} 01>,<\mathrm{F} 002, \mathrm{~S} 02>,<\mathrm{F} 003, \mathrm{~S} 04>,<\mathrm{F} 004, \mathrm{~S} 02>$, $<$ F005, S04 $>$ );

Causation=" Roller skew is too large, thrust bearing is too big, bearing inner cooling water pipe leakage, lubricating oil for a long time did not change in lubrication device failure";

Action=" Straightening roller position, eliminate the skew Angle, replace the water pipe to eliminate leakage phenomenon, change of new heavy duty industrial lubricants";

Evaluation=" Bearing shell temperature back to normal";

Similarity $=0$;

\}

\section{Organization and Index of Fault Cases}

Case index can make a distinction between one and others. The design of case index is an important part of CBR, especially when the fault case library is big. Case's index good or bad will directly affect the retrieval speed and accuracy.

Hierarchical structure of the fault case can facilitate the reuse of fault cases. The case of the same fault mode generally contain common features, have common characteristics of cases can be divided into category, others common feature of fault is divided into another kind, the level of abstraction model can help retrieve fault case quickly.

Aiming at the problems in the operation of the cement rotary kiln, the hierarchical structure model is built as Figure 2. 


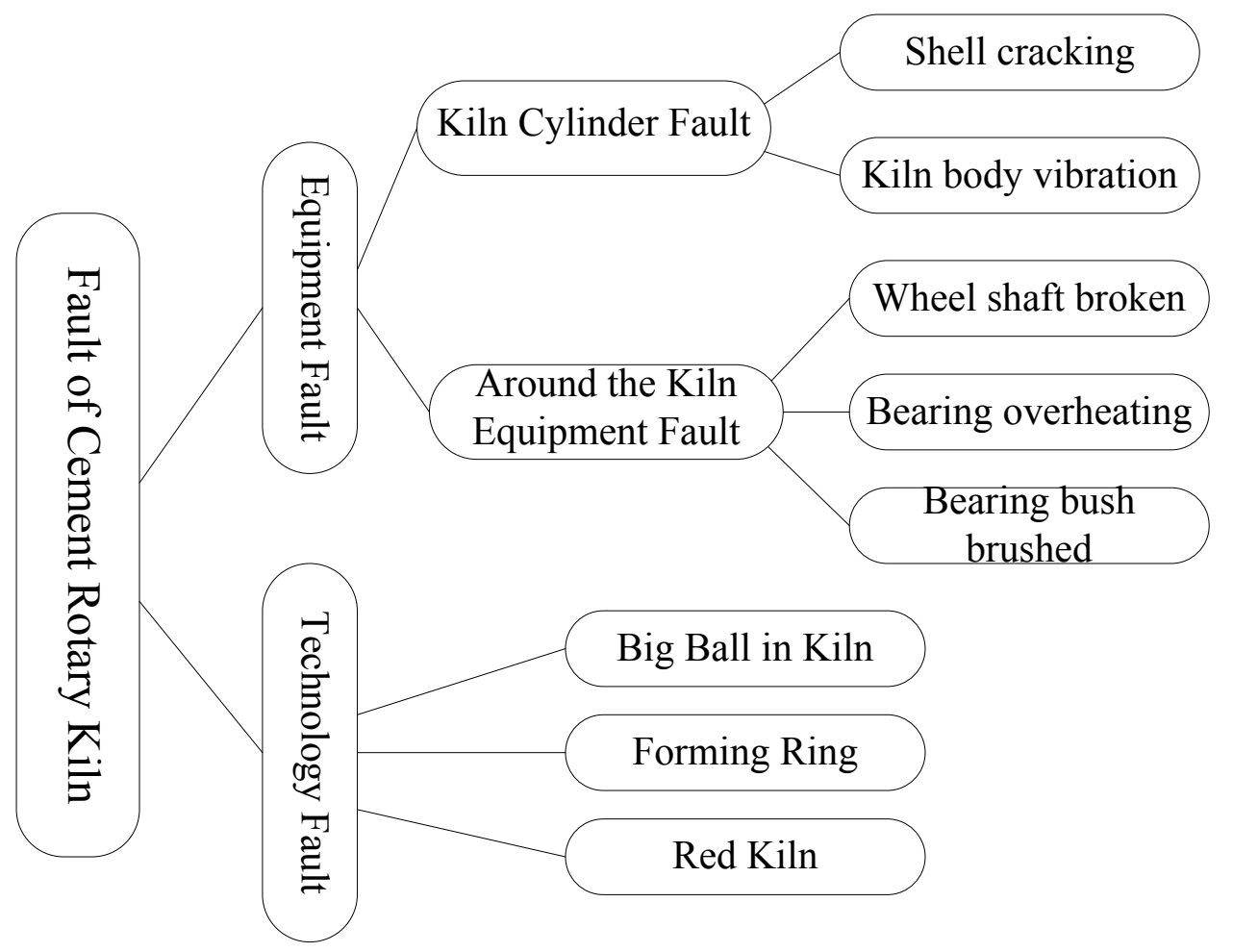

Figure 2.The hierarchical structure model of cement rotary kiln faults

When fault cases are organized, a suitable index mechanism is required. A good index mechanism can make user retrieve fault cases quickly and accurate. Object oriented fault case representation method provides great convenience for quick retrieval. Case index is the only to distinguish the different cases. Using object-oriented fault case, each case has its own CaseID property. This property can be used as an index of keywords. Storage of the cement rotary kiln fault cases, kiln cylinder fault begins with YT, around the kiln equipment fault begins with YZ, the process fault begins with GY, so using CaseID can retrieval to the same or similar fault cases quickly. Fault cases and the corresponding CaseID of the cement rotary kiln, such as Table 1.

Table 1.Fault cases and the corresponding CaseID of the cement rotary kiln

\begin{tabular}{ll}
\hline Fault Case & CaseID \\
\hline Shell Cracking & YT001 \\
Kiln Body Vibration & YT002 \\
Wheel Shaft Broken & YZ001 \\
Bearing Overheating & YZ002 \\
Bearing Bush Brushed & YZ003 \\
Big Ball in Kiln & GY001 \\
Forming Ring & GY002 \\
Red Kiln & GY003 \\
\hline
\end{tabular}

\section{Case Similarity Matching}

Case similarity matching is one of the most critical steps in CBR. According to case similarity determines how much they like between new case and fault cases stored in library as to avoid the phenomenon of case does not match. Because of the cement rotary kiln parameter changes in a proper range, in other words, parameters is in a fixed interval, Similarity matching problem can use Slioim represented by the proposed numerical method for solving the interval similarity ${ }^{[3,4]}$. $\left[a_{1}, a_{2}\right]$, $\left[b_{1}, b_{2}\right]$ are two child interval of $[\alpha, \beta]$, then the degree of similarity between subinterval $\left[a_{1}, a_{2}\right]$ and $\left[\mathrm{b}_{1}, \mathrm{~b}_{2}\right]$ as follows. 


$$
\begin{aligned}
& \operatorname{Sim}\left(\left[a_{1}, a_{2}\right],\left[b_{1}, b_{2}\right]\right)=\frac{\int_{a_{1}}^{a_{2}} \int_{b_{1}}^{b_{2}} \operatorname{sim}(x, y) d y d x}{\left(a_{2}-a_{1}\right)\left(b_{2}-b_{1}\right)}= \\
& \left\{\begin{array}{l}
1-\frac{b_{2}+b_{1}-a_{2}-a_{1}}{2(\beta-\alpha)}, a_{2} \leq b_{1} ; \\
1-\frac{3\left(b_{2}-b_{1}\right)\left(b_{1}-a_{1}\right)\left(b_{2}-a_{1}\right)}{6\left(a_{2}-a_{1}\right)\left(b_{2}-b_{1}\right)(\beta-\alpha)}- \\
\frac{\left(a_{2}-b_{1}\right)^{3}+\left(a_{2}-b_{2}\right)^{3}+\left(b_{2}-b_{1}\right)^{3}}{6\left(a_{2}-a_{1}\right)\left(b_{2}-b_{1}\right)(\beta-\alpha)}, \\
\frac{b_{1}<a_{2} \leq b_{2} ;}{1-\frac{b_{2}{ }^{2}+b_{1}{ }^{2}+b_{1} b_{2}}{3\left(a_{2}-a_{1}\right)(\beta-\alpha)}-} \\
\frac{a_{2}{ }^{2}+a_{1}{ }^{2}-\left(a_{2}+a_{1}\right)\left(b_{2}+b_{1}\right)}{2\left(a_{2}-a_{1}\right)(\beta-\alpha)}, b_{2}<a_{2} .
\end{array}\right.
\end{aligned}
$$

When $a_{1} b_{1}$, switch $a_{1}$ and $b_{1}, a_{2}$ and $b_{2}$, respectively, Equation (2) still can be used in solving two intervals similarity.

\section{Application Instance}

In new dry process cement production, process parameters measuring point is not all the same in different cement enterprises, but the main process of cement rotary kiln system monitoring parameters are the same, these parameters related to the cement quality, so they are very important to cement production ${ }^{[5]}$. These parameters are Kiln Primary Motor Current (allowing range between $700 \mathrm{~A}$ and $820 \mathrm{~A}$ ), Rear Gas Temperature (allowing range between $950{ }^{\circ} \mathrm{C}$ and $820{ }^{\circ} \mathrm{C}$ ), Negative Pressure of Kiln Terminal (allowing range between -500 Pa and $0 \mathrm{~Pa}$ ), Negative Pressure of Kiln Head (allowing range between $-100 \mathrm{~Pa}$ and $0 \mathrm{~Pa}$ ), Primary Cyclone outlet temperature of Preheater (allowing range between $280{ }^{\circ} \mathrm{C}$ and $340{ }^{\circ} \mathrm{C}$ ), Calciner outlet temperature (allowing range between $850{ }^{\circ} \mathrm{C}$ and $\left.900{ }^{\circ} \mathrm{C}\right)$.

\section{Characteristic Analysis}

Kiln primary motor current reflects the kiln skin conditions and if forming a ring or a big ball in the kiln motor current will rises. Negative pressure of kiln tail and Negative pressure of kiln head reflect ventilation balance of kiln system. Calciner outlet temperature is characterization of materials precalcining situation inside the furnace and it has important significance in controlling the meal rate and preventing of decomposition furnace preheating system congestion.

\section{Case Similarity Matching}

According to the characteristics of selection, using nearest neighbor retrieval model calculate similarity between the new fault and the existing five cases in library, the parameter values in Table 2. 
Table 2. Parameters of the cement rotary kiln

\begin{tabular}{|c|c|c|c|c|c|c|c|}
\hline $\begin{array}{l}\text { Technological } \\
\text { Parameters }\end{array}$ & $\begin{array}{c}\text { Primary } \\
\text { Cyclone } \\
\text { Outlet } \\
\text { Temperature } \\
\text { of Preheater } \\
{\left[{ }^{\circ} \mathrm{C}\right]}\end{array}$ & $\begin{array}{c}\text { Calciner } \\
\text { Outlet } \\
\text { Temperature } \\
{\left[{ }^{\circ} \mathrm{C}\right]}\end{array}$ & $\begin{array}{c}\text { Tail Gas } \\
\text { Temperature } \\
{\left[{ }^{\circ} \mathrm{C}\right]}\end{array}$ & $\begin{array}{l}\text { Kiln } \\
\text { Primary } \\
\text { Motor } \\
\text { Current } \\
\text { [A] }\end{array}$ & $\begin{array}{c}\text { Negative } \\
\text { Pressure of } \\
\text { Kiln Tail } \\
{[\mathrm{Pa}]}\end{array}$ & $\begin{array}{c}\text { Negative } \\
\text { Pressure of } \\
\text { Kiln Head } \\
{[\mathrm{Pa}]}\end{array}$ & Similarity \\
\hline Case 1 & {$[200,220]$} & {$[950,980]$} & {$[1100,1200]$} & {$[750,800]$} & {$[-200,0]$} & {$[-50,-20]$} & 0.44 \\
\hline Case 2 & {$[280,320]$} & {$[800,820]$} & {$[900,930]$} & {$[640,670]$} & {$[-400,-100]$} & {$[-100,-50]$} & 0.615 \\
\hline Case 3 & {$[300,320]$} & {$[860,890]$} & {$[910,940]$} & {$[830,880]$} & {$[-700,-600]$} & {$[-20,0]$} & 0.993 \\
\hline Case 4 & {$[280,320]$} & {$[850,890]$} & {$[880,910]$} & {$[820,860]$} & {$[-400,-200]$} & {$[-40,-20]$} & 0.884 \\
\hline Case 5 & {$[270,320]$} & {$[850,910]$} & {$[950,1000]$} & {$[650,700]$} & {$[-700,-650]$} & {$[-200,-100]$} & 0.723 \\
\hline New fault & {$[300,320]$} & {$[870,890]$} & {$[910,930]$} & {$[840,880]$} & {$[-650,-600]$} & {$[-10,0]$} & - \\
\hline Ratio & 0.15 & 0.2 & 0.15 & 0.2 & 0.15 & 0.15 & - \\
\hline$\alpha$ & 200 & 800 & 900 & 640 & -700 & -200 & - \\
\hline$\beta$ & 320 & 980 & 1200 & 890 & 0 & 0 & - \\
\hline
\end{tabular}

Annotation: $\alpha, \beta$, in Table 2 , respectively express each technological parameter of minimum and maximum.

According to the method of computing similarity put forward by Slioim, the similarity between new fault case and case 1 as follows.

$\operatorname{Sim}_{\text {Primary Cyclone Outlet Temperature of Preheater }}([200,220],[300,320])=0.167$

Sim Calciner Outlet Temperature $([950,980],[870,890])=0.528$

$\operatorname{Sim}_{\text {Tail Gas Temperature }}([1100,1200],[910,930])=0.233$

$\operatorname{Sim}_{\text {Kiln Primary Motor Current }}([750,800],[840,880])=0.66$

$\operatorname{Sim}_{\text {Negative Pressure of Kiln Tail }}([-200,0],[-650,-600])=0.25$

$\operatorname{Sim}_{\text {Negative Pressure of Kiln Head }}([-50,-20],[-10,0])=0.7$

Combined with the recent adjacent method to calculate the similarity of the case 1 and the new fault as follows.

$\operatorname{Sim}($ case 1, New Fault $)=0.2 \times(0.528+0.66)+0.15 \times(0.167+0.233+0.25+0.7)=0.44$

Calculated similarity between new fault case and case 2 , case 3 , case 4 , case 5 , the results are as follows.

Sim $($ case 2, New Fault $)=0.615$

Sim $($ case 3, New Fault $)=0.993$

Sim $($ case 4, New Fault $)=0.884$

Sim $($ case 5, New Fault $)=0.723$

Choose Best Case

Select the highest similarity two cases, case 3 and case 4, because of case 3 and new fault case have extremely high similarity degree, so preliminary diagnosis for case 3 can be represented by new fault.

Case Reuse and Solve Fault

According to the cement enterprise central control room operator's long-term accumulation of operating experience, case 1 and case 2 signify blocking of the cyclone canister; case 3 signify forming a ring at the behind of kiln; case 4 signify peeling the clinker coating; case 5 signify raw material run away. After diagnosis, the new fault is the same with case 3. They both have ring at the behind of kiln. Using the kiln ring fault treatment scheme just like reduce the raw meal feeding rate, prolong furnace flame length can solve the problem. 


\section{Summary}

CBR method simulates the human way of thinking and it has strong ability of autonomous learning. When an adjusted new fault case is greater than the threshold value user can add this new case to the case library. It provides convenience for the next fault diagnosis. Cement rotary kiln monitoring parameters are fixed, the record is rich, case library can store a lot of fault cases, which provides great convenience for CBR diagnosis. Overall, CBR diagnosis technology is a branch of artificial intelligence and it has the important status in fault diagnosis, but its research and application is still in the exploratory stage, but with the increase of the depth of research, CBR diagnosis technology will become an efficient method in the field of fault diagnosis.

\section{References}

[1] Aijun YAN, Tianyou CHAI, Pu WANG. The Shaft Furnace Fault Forecasting System Based on Case-Based Reasoning [J]. Journal of Control and Decision, 2008, 23(2) 177-181.

[2] Donghao LIN.Using Case-Based Reasoning to Establish Expert System, Computer and Modernization,1996,3 35-37.

[3] Slonim T Y, Schneider M. Design Issues in Fuzzy Case-based Reasoning [J]. Fuzzy Sets and Sy stem s, 2001, 117(2) 251-267.

[4] Kaibo ZHOU,Shan FENG,Feng LI. Based on the Similarity Calculation Model of the Case Attribute of the Study [J]. Journal of Wuhan University of Technology (Engineering information and management), 2003,25(1) 24-27.

[5] Kai REN, Jinyun PU. Based on the Similarity of Case Attributes Interval Algorithm Research [J]. Journal of Control and Decision, 2010, 25(2) 308-310.

[6] Dongmei ZHANG. NSP Cement Production Technology and New Equipment Introduction [M]. Silicon Valley,2008(22) 98. 